\title{
Zhu Yuanzhang Think-tank Construction Theory
}

\author{
Dongxia Song \\ School of public administration, Yancheng Teachers University, Yancheng 224051, China
}

Keywords: Zhu Yuanzhang, Literacy, Liu Ji etc.

\begin{abstract}
A founder of the Ming dynasty zhu yuanzhang in its regime before and after the construction of a think-tan extremely seriously,this is not only reflected in the vdlue of the ideas of "liberal", what is more important in the concrete actions,acceptance,dependenton people with this from the revised "ming" high frequency "wery close", "charged with heart", the words such as "pet ceremony and even" can see, he of the "brain”, "extended mind” for his victory over pack and eventually reaching the top of power play a key role.
\end{abstract}

\section{Introduction}

Although Zhu Yuanzhang was born of a civilian family and often claimed himself humbly as "rising from a farmer household”, “coming from a humble background”, “a civilian from south of Yangtze River" and "a civilian from west of Huaihe River", the admirable thing is that he had a very deep and unique understanding of "educated people". In his view, "listening to discussion among Confucian Scholars can develop the intelligence". "1] Thus he did his utmost to visit and find talents during development of his power. Li Jinglong, Xie Jin and some other people commanded Zhu Yuanzhang in the Veritable Records of Taizu: "outstanding figures come together without an appointment and follow him without an order; he gathers the talented persons to save people from the troubled times". ${ }^{[2]}$ This indicates Zhu Yuanzhang's strong desire of seeking talents and governing the state jointly with talented people. In fact, when incorporating his own forces and expanding his power, he would definitely visit the local literate people wherever he went and would gather them under his command to offer advices and suggestions to him. With such think banks, Zhu Yuanzhang expanded his power step by step, developed his career rapidly and finally achieved his hegemony.

\section{Zhu Yuanzhang and Feng Brothers}

Feng Guoyong and Feng Guosheng, the Feng Brothers, "were fond of reading and proficient in art of war, and united mountain villages to protect themselves at the end of Yuan Dynasty". After the capture of Dingyuan, the Feng Brothers followed Zhu Yuanzhang. Seeing that they wore Confucian clothing, Zhu Yuanzhang learned that they were intellectuals, and "it is more like seeing trusted followers". ${ }^{[3]}$

When Zhu Yuanzhang asked them for advices about winning the state power, Feng Guoyong answered with confidence: "Jinling is a strategically situated place and suitable imperial capital, which should be occupied as the base. Then, you should conquer other places, advocate the thought of benevolence and righteousness, win popular support and never get greedy for women and treasure. In this way, it is easy to unify the state.” [3]

Feng Guoyong was not only full of learning, but also possessed of a second sight: "Taizu captured Chen Yexian but then released him and ordered him to recall his troops. Feng Guoyong predicted that Chen Yexian would betray him and that it was difficult to get him remanded." [3] As expected, Chen 
Yexian did not recall his troops for Zhu Yuanzhang, but took the opportunity to betray him and almost brought disasters.

Living up to the great hope of Zhu Yuanzhang, Feng Guoyong won battle achievements repeatedly and was regarded highly: "he rendered great service in conquering Chuzhou and Hezhou, occupying Sancha River, Banmen Village and Jilong Mountain. Thus, Feng Guoyong was appointed as the trusted subordinate to lead his bodyguards in crossing rivers and conquering Taiping."

In view of remarkable achievements of Feng Guoyong, the writer of the History of Ming Dynasty recorded the following words of praise at the end of Volume 129: "Both Fengsheng and Fu Youde were valiant generals who participated in hundreds of wars. According to the ranking of meritorious courtiers and the praises of Taizu of Ming, they occupied the same position of Tang He and Dengyu”. Namely, Zhu Yuanzhang's appreciation and praise of Feng Guoyong were not less than those of Tang $\mathrm{He}$, a meritorious courtier for state establishment, and Deng $\mathrm{Yu}$, a famous general. There was a tendency that the late comers may be more outstanding.

\section{Zhu Yuanzhang and Li Shanchang}

When marching to Chuzhou, Zhu Yuanzhang gave an interview to Li Shanchang, a Dingyuan native, who was a local knowledgeable and wise celebrity: "He studied early in his childhood and was knowledgeable; besides, having learned the Legalists' thought, he played very carefully with every conceivable possibility taken into account. When Taizu captured Chuyang, Shanchang paid a visit to Taizu, who then treated him with respect and appointed him as prefectural secretary after knowing him as a senior in the town". ${ }^{[4]}$ Zhu Yuanzhang once consulted him that "when would the war stop". Li Shanchang answered leisurely: "in the troubled times of Qin dynasty, Han Gaozu, who was a civilian, was open-minded and magnanimous, discovered able people and put them at suitable posts, and didn't prefer killing people, so it only took five years for him to become an emperor. Today, the world in Yuan dynasty is in disorder and may fall apart. You are from Haozhou, which is not far from Peixian County, so you should accept the king's bearing of mountains and rivers. If you learn from Han Gaozu's actions, the world can be pacified easily." ${ }^{[4]}$ With a nod approval of this advice, Zhu Yuanzhang desired to become an emperor like "Han Gaozu" from then on. Accordingly, Li Shanchang also gained Zhu Yuanzhang's trust and was put in an important position: "he went to Chuzhou together with Zhu Yuanzhang as his adviser, involved the planning of important affairs took charge of gifts, provisions and funds of the troops. It was obvious that Zhu Yuanzhang trusted him very much." [4] However, unfortunately, Zhu Yuanzhang almost completely copied Liu Bang's actions without criticizing them and even went farther than Liu Bang. As described in Zhao Yi's comments: "Zhu Yuanzhang even followed the examples of Han and Peng to put Hu and Lan into prison and kill meritorious courtiers. This is because he overdid it”. ${ }^{[4]}$ As a result, it was inevitable that he went astray.

However, the the unique status of Li Shanchang in the political circle of early Ming dynasty against the characteristics of centralized politics in the feudal society determined the necessity of Li Shanchang's unfortunate ending in his later years. Volume 127 of the History of Ming Dynasty analyzed this in the final words of praise and made a conclusion to the point: “... he became extraordinarily rich. When he became advanced in years, he rode for a fall."

\section{Zhu Yuanzhang and Zhu Sheng}

After Zhu Yuanzhang occupied Huizhou in 1358 (the $18^{\text {th }}$ year of Zhizheng Period), his military officer recommended to him the old Confucian scholar Zhu Sheng from Xiuning. It was said that this person was fond of learning: "He passed the provincial civil service examination the end of Yuan Dynasty, was appointed as the director of education in Chizhou and did well in this position. As robbers arose from all quarters, he gave up his post and lived in seclusion in Shimen. In spite of eluding turmoil frequently, he insisted on reading everyday." [6] Zhu Yuanzhang desired greatly to 
call in Zhu Sheng for consultation about current affairs. ${ }^{[6]}$ Seeing that Zhu Yuanzhang has extraordinary gumption and is considerate and kind to men of talent, Zhu Sheng with higher knowledge told him the "nine-word principle": "consolidate the base, reserve sufficient army provisions and slow down the winning of state power". With this strategy, Zhu Yuanzhang was kept from becoming the target of public criticism early; besides, he was inspired a lot from the overall strategy. Thus, Taizu praised and accepted this suggestion with pleasure. ${ }^{[6]}$

Besides the "nine-word principle", Zhu Sheng had also made other contributions to Zhu Yuanzhang, such as compilation of history books and establishment of etiquettes, which were very influential in the academic circle of that period. ${ }^{[6]}$

\section{Zhu Yuanzhang and the"Four Scholar”}

After conquering Jinhua and Qingtian in 1359 (the $19^{\text {th }}$ year of Zhiyuan Period in Yuan Dynasty), Zhu Yuanzhang asked Li Shanchang whether there are scholars among the local people, and Li Shanchang recommended the hermit Liu Ji to him. Liu Ji was extremely wise since his childhood, and his teacher Zheng Fuchu once told his father Liu Yueyan: "this child will certainly have a great achievement in future and make his ancestors illustrious". ${ }^{[7]}$

Zhu Yuanzhang invited Liu Ji respectfully just like Liu Bei making three calls at the thatched cottage of Zhuge Liang: “After conquering Jinhua and Kuocang, Taizu heard the fame of Liu Ji, Song Lian and some other persons and then employed them with currency. Liu Ji did not agree with such employment, thus the officer Sun Yan wrote a letter to invite him again; Liu Ji took the post finally.” Then, Liu Ji presented the "Eighteen Suggestions for Current Affairs”. Because of this, Zhu Yuzhang was very excited and established a courtesy accommodation for settling down Liu Ji and some other persons; Liu Ji was highly treated and respected". ${ }^{[7]}$

The Biography of Zhang Yi in History of Ming Dynasty recorded the scene that Zhu Yuanzhang met Liu Ji, Song Lian, Ye Chen and Zhang Yi: “Taizu asked Liu Ji and other persons to sit down and said: 'I invited you for the peace of the state. Now the state is in ceaseless disputes, and when can we pacify it"”? Zhang Yi answered: "the nation is constantly changing, and only the morality is the assistance; only the person without the fondness of killing people can dominate the state". That is, Zhu Yuanzhang could win people's hearts and obtain the dominant position as long as he protects his civilians. Taizu praised his answer, thought highly of his suggestions and appointed him as the assistant steward. ${ }^{[7]}$

It is particularly worth mentioning that Liu Ji made great contributions to strategic deployment, ambush at Yingtian, ascending ceremony, etc. At that time, Zhu Yuanzhang were in the face of two big obstacles, Chen Youliang and Zhang Shicheng; the governing group had different opinions on eliminating Chen Youliang or Zhang Shicheng firstly; thus Zhu Yuanzhang asked Liu Ji for suggestions. On the basis of clear analysis on the objective situation, Liu Ji determined the strategy of eliminating Chen Youliang firstly: "Zhang Shicheng relies on ramparts to defend and it is not enough to worry about. Chen Youliang seizes monarch and threatens liegemen, and his place is at the upstream; he had never forgotten to kill us; it is better to eliminate him firstly. After he is eliminated, Zhang Shicheng is weak and alone and can be eliminated upon attack. Then we continue our attack towards the central plain in the north and accomplish the gaining of state power". ${ }^{[7]}$ The development of the situation was also basically the same as what Liu Ji predicted: "the battle was locked in a stalemate in three days. Liu Ji requested for moving the force to the Hukou area and eliminating him there on the Venus-Jupiter conflict day. After Chen Youliang was eliminated, Taizu captured Zhang Shicheng, continued the attack towards the central plain in the north and finally accomplished the great empire as Liu Ji expected”. ${ }^{[7]}$ Liu Ji was hereby highly treated and respected by Zhu Yuanzhang: "Taizu listened to me with respect, called me respectful teacher but not my name, and said 'you are my adviser"," [7]

All of the "Four Scholars" played very important roles in the career development of Zhu Yuanzhang, and it is said at the end of Volume 128 of the History of Ming Dynasty: "Liu Ji and Song 
Lian have broad academic knowledge, write classical articles and are great academic masters. Liu Ji devises strategies within a command tent, while Song Lian assists Taizu in an unhurried manner and with loyalty and caution in governing the state at the beginning of state founding and is an excellent courtier assisting the emperor in governing the state. Zhang Yi spares no efforts to govern a province, and Ye Chen sacrifices himself to achieve his will. They have talent and political integrity, have achieved their remarkable careers and indeed live up to the praise of recruiter”.

\section{Zhu Yuanzhang and Tao An}

Tao An (secondary personal name, Wang Jing), was born in Gushu. "He was smart and ambitious, extensively read classics and histories and had an extraordinarily profound command of the Book of Changes”. After Taizu raised an army and captured Taiping after crossing over the river from Hezhou, Tao An and Li Xi, an old Confucian scholar, leaded their fellow men to welcome Taizu out of town. "After seeing Taizu, Tao An immediately told his fellow men: seeing your outstanding appearance, I know you are not an ordinary person. We finally have our leader now."'Zhu Yuanzhang also urgently asked Tao An about his opinion on the current situation. Tao An said: "many heroes are fighting in the hope of conquering the world in such a troubled times but they only seize cities and massacre all the inhabitants, because they only aim at obtaining beauties, properties and interim happiness instead of saving people out of the disordered world. However, you leaded your army to cross over the river but didn't massacre people, so people heartily acknowledge allegiance to you. For this reason, you should follow the god's will to send armed forces to save the world. You'd better seize Jinling to become an emperor; then, the world can be pacified”. It is clear that Tao An hoped Zhu Yuanzhang to "go against the hope of all heroes", don't kill people arbitrarily, don't rob properties from people, don't burn up people's houses, conquer Jinling and participate in wars all around; then, he would be invincible. Highly praising him, Zhu Yuanzhang appointed Tao An as Secretarial clerk of Antianxia Xingguoyi Marshal Headquarter. ${ }^{[8]}$

Tao An was very modest and low-profile: "Taizu asked Tao An how to evaluate Liu Ji, Song Lian, Zhang Yi and Ye Chen, Tao An said: I'm not so good as Liu Ji in astuteness and resourcefulness, don't have so much knowledge as Song Lian and my skills in ruling people was not as good as that of Zhang Yi and Ye Chen. Tai Zu has so many talented people”. ${ }^{[9]}$ Modesty was shown between the lines.

There are comments on the contributions of Zhu Yuanzhang's think tank, especially the achievement in establishing rituals and music, in Volume 136 of the History of Ming Dynasty: when setting the etiquette system in the early Ming dynasty, because Song Lian just got retired, Tao An needed to judge all etiquettes. The etiquettes of great sacrifice were mainly determined by Tao An and the remaining etiquettes were based on all courtiers' ideas. Zhan Tong took charge of the emperor's grand ceremony of ancient sacrifice; Zhu Sheng took charge of sacrifice for four seasons in the Imperial Ancestral Temple; Qian Yong took charge of sacrifice to previous sages and ploughing activities; Cui Liang took charge of Renwuji; Liu Ji took charge of morning exercise; Wei Guan took charge of the blessing sacrifice; Tao Kai took charge of military etiquette; all of them could set these etiquettes according to the classics and books and ancient events, so the era was prosperous under the wise governance. All the great decisions were made by the emperor, we could not ignore the courtiers' contributions. All such external brains of Zhu Yuanzhang were very loyal and spared no efforts so the function of the think tank was given full play to reach the expected goals.

Other members of the think tank included Hu Dahai and Liao Yongan etc. It cannot be unnoticed that Zhu Yuanzhang could fortunately meet Liu Ji, Song Lian, Ye Chen and Zhang Yi because of Hu Dahai's recommendation. ${ }^{[10]}$ There is an objective comment in the end of Volume 133 in the History of Ming Dynasty: “After raising an army, the Yongle emperor decided to cross over the river, strove hard in thousands of miles in the southeast region, destroyed Chen Youliang and Zhang Shicheng's army, conquered the central plains in the north, and captured Fu Jian and Guangdong in the south; Liao Yongan and Hu Dahai's great achievements could not be described detailedly. They always 
made a decision rapidly without hesitation and devoted themselves in the battlefield. Even though their great achievements were unfulfilled, the court praised them in many ancient books.”

After the regime was consolidated, the relationship between Zhu Yuanzhang and the members of his think tank could not be the same as before. For instance, after all, Liu Ji was a scholar, even though felt Zhu Yuanzhang, who shared weal and woe with him in the past, unpredictable, he still fulfilled his duties on the jig after repeated releasing and recalling. He tried to persuade Zhu Yuanzhang: "A sunny spring must come after frost and snow. Now that the national prestige has been established, it is better to make remedies with kind measures.” ${ }^{[11]}$. He hoped that Zhu Yuanzhang could reserve some dignity for courtiers instead of humiliate them frequently. Unfortunately, at that time, Zhu Yuanzhang couldn't accept such advices. Circumstances change with the passage of time. Their treatment cannot be compared with the past. As Zhao Yi said: “Only the Yongle emperor became the emperor of the world with the assistance of numerous courtiers but killed all of them after pacifying the world. His cruelty was unprecedented, perhaps because it's his nature of being suspicious and found of massacre.” [5]

\section{Effect: necessity of success (on behalf of conclusion)}

Han Gaozu, Liu Bang, said: "I can become an emperor because I have three outstanding talents”. [6] Zhu Yuanzhang, the Yongle emperor, thought his think tank was superior to that of Liu Bang, so he was reasonably confident that his cause would be more glorious than that of Liu Bang: "our Ming dynasty originated from Zhao Xing with multifold Marquesses than Han dynasty; Li Hangong' s (Shanchang) meritorious service was the same as Xiao He' s ; the general Xu Weigong (Da) is slightly better than Han Xin; Liu Chengyi' s (Bowen) wisdom is equal to that of Zhang Liang; Chang Yuchun, Li Wenzhong and Fu Youde et al are the accompaniment of the three outstanding talents. The 18 generals are left far behind. Even compared with Han Gaozu, our dynasty also has outstandingly meritorious deed. The great achievement of building a country is not occasional” . Because of such social elites, Zhu Yuanzhang had his horizon broadened and his ambition enhanced and finally made his own marvelous achievement.

Meanwhile, Zhu Yuanzhang also had his cultural quality improved in the process of discovering talents and building his think tank. Besides, in the military practice of leading troops in wars and his later political governing activities, Zhu Yuanzhang could casually quote sentences from the Four Books and Five Classics, The Art of War and official histories of previous dynasties, give comments easily and even "write articles" thoughtlessly. ${ }^{[7]}$ The historian of Ming dynasty also made comments on this: "the emperor was analphabetic in his childhood. After raising an army, he increasingly got close to the Confucianism scholars and read many books etc. Even the men of letters didn't make so many efforts in learning". ${ }^{[8]}$ Even though this is a flattering comment, it is undoubtedly true that he improved his cultural accomplishment. Zhu Yuanzhang was also very conceited about his becoming talented through diligent self-study in the dangerous environment of warfare and once complacently showed off to his courtiers: "I was a peasant in the past and didn't get a teacher to teach me; however, I still can read books, write articles and get enlightened, it means I am a born emperor ". ${ }^{[9]}$ It is true that he was self-dramatizing but it is an objective fact that he upheld cultural education and this should be affirmed. However, all of these were undoubtedly related to the influence and permeation of the members of his think tank. Zhu Yuanzhang's highly praising of Confucianism was even inherited until the Emperor Wuzong: "the emperor was not educated originally but his sagacious character was formed. When suddenly hearing the tenet of books he never heard before, he applied them in his practical governance and created the over a hundred years of peaceful ruling. His remaining contributions lasted until Zhengde period.” ${ }^{[10]}$ Thus, it is evident that his influence was great and far-reaching.

Zhao Yi, historian of Qing dynasty, said: "the Yongle emperor was a person integrating the characters of sage, hero and thief”. ${ }^{[11]}$ Zhu Yuanzhang was exactly such a colorful person with 
heroism, hooliganism and spirit of man of letters. This inevitably determined the later generations' mixed reception of him. His strange personality, legendary life experience, fluctuating pioneering history and his own unique techniques of governance and employment of talents are very intriguing and thought-provoking.

\section{References}

[1] Written by Zhao Yi and corrected by Wang Shuming. History of Ming Dynasty - the Yongle Emperor's Affection of Confucianism in Volume 36 of Some Thoughts on 22 Histories. Beijing: Zhonghua Book Company, 1984.

[2] The Memoir of Ming Dynasty. Printed copy of the Research Institute of History and Language of the Central Academy, book 1.

[3] [3]Biography of Fengsheng in Volume 129 of the History of Ming Dynasty. Beijing: Zhonghua Book Company, 1974.

[4] The History of Ming Dynasty- Yongle Emperor's Imitation of Han Gaozu in Volume 32 of Some Thoughts on 22 Histories.

[5] The History of Ming Dynasty- Hu Weiyong and Lan Yu’s Imprisonment in Volume 32 of Some Thoughts on 22 Histories.

[6] [Ming dynasty] Zhang Mao. Miscellaneous - Reading of the History of Western Han Dynasty in Volume 3 of Collection of Works written in Fengshan. Photocopy of Complete Library in Four Branches of Literature, Volume 1254.

[7] Edited by Deng Shilong and mainly proofread by Xu Daling and Wang Tianyou. Unofficial History of Jiansheng (Xu Zhenqing). Allusion of Ming Dynasty. Beijing: Peking University Press, 1993.

[8] Written by Tan Qian and proofread by Zhang Zongxiang. March 27 of the 26th Year in the Zhizheng period in Volume 2 of Guoque. Beijing: Zhonghua Book Company, 1958.

[9] Edited by Deng Shilong and mainly proofread by Xu Daling and Wang Tianyou. Unofficial History of Jiansheng (Xu Zhenqing). Allusion of Ming Dynasty. Beijing: Peking University Press, 1993.

[10]History of Ming Dynasty - the Yongle Emperor's Affection of Confucianism in Volume 36 of Some Thoughts on 22 Histories.

[11]History of Ming Dynasty - the Yongle Emperor's Seizure of a Country via his Objection against Massacre in Volume 36 of Some Thoughts on 22 Histories. 